\title{
Internet of Things Enabled Technologies for Behaviour Analytics in Elderly Person Care: A Survey
}

\author{
Lee Newcombe, Po Yang, Chris Carter and Martin Hanneghan \\ Department of Computer Science, \\ Liverpool John Moores University, \\ Liverpool, L3 3AF, UK \\ L.S.Newcombe@2012.ljmu.ac.uk, \{ P.Yang, C.J.Carter, M.B.Hanneghan\}@ljmu.ac.uk
}

\begin{abstract}
The advances in sensor technology over recent years has provided new ways for researchers to monitor the elderly in uncontrolled environments. Sensors have become smaller, cheaper and can be worn on the body, potentially creating a network of sensors. Smart phones are also more common in the average household and can also provide some behavioural analysis due to the built in sensors. As a result of this, researchers are able to monitor behaviours in a more natural setting, which can lead to more useful data. This is important for those that may be suffering from mental illness as it allows for continuous, non-invasive monitoring in order to diagnose symptoms from different behaviours. However there are various challenges that need to be addressed ranging from issues with sensors to the involvement of human factors. It is vital that these challenges are taken into consideration along with the major behavioural symptoms that can appear in an Elderly Person. For a person suffering with Dementia, the application of sensor technologies can improve the quality of life of the person and also monitor the progress of the disease through behavioural analysis. This paper will consider the behaviours that can be associated with dementia and how these behaviours can be monitored through sensor technology. We will also provide an insight into some sensors and algorithms gathered through survey in order to provide advantages and disadvantages of these technologies as well as to present any challenges that may face future research.
\end{abstract}

Index Terms - Internet of things, healthcare, behaviour analytics

\section{INTRODUCTION}

It is currently estimated that 1 in 5 people over the age of 65 will develop dementia, with an estimated 850,000 currently living with some form of the disease [1]. In order to measure and conceptualize Dementia related behavioural symptoms, it is essential that the disease is understood. Dementia has two major symptom groups: cognitive dysfunction symptoms as well as symptoms of behavioural and psychological signs [2]. The behavioural symptoms of the disease include combinations of changes in physical movement and speech. One such example of a change to a dementia person's behaviour is agitated behaviour [3]. Speech ability in a person suffering from dementia can cause communication challenges, however maintaining effective communication increases the quality of life for the person as persons suffering from dementia can frequently struggle to find the appropriate words to describe objects. Various behavioural symptoms of dementia such as depression and anxiety can be caused by the difficulties that persons suffering with dementia have with communication [4].

Alternative occurrences of behavioural dementia symptoms include sleep disturbances, withdrawal and apathy. Behavioural dementia symptoms can vary between individuals in repeated occurrences as well as the symptoms that become present in a person. Clusters of behavioural symptoms can also occur in a person which can make characterizing the symptoms significantly more complicated [3]. In some circumstances, clinical applications monitor behaviour through direct observation of the person. However these applications only consider whether the behaviour is present or absent, only few applications consider the intensity of the behavioural symptoms that are present [3].

Behaviour change approaches typically involve the direct observation of real life settings and behaviour change principles to enhance the quality of life of people who suffer with dementia. Presently, there are several theoretical and computational frameworks for modelling dementia related behavioural excesses (wandering, disruptive vocalisations), behavioural deficits (incontinence, self-feeding) and mood changes (depression) for critical care and hospital care environments [5]. However, in order to use these frameworks, large-scale ambient sensing systems have to be deployed which are expensive to implement and only viable in a hospital care environment.

Pervasive healthcare applications have become fairly common over the past decade [6], with many applications taking advantage of recent technological developments in the mobile and wearable device market. Developers of these devices of continually improving upon the technology used to add more processing power, storage space and even adding new sensors into these handheld and wearable devices. Pervasive healthcare applications developed for these platforms can be used to provide assistance to those with disabilities such as communication issues, or to monitor and evaluate the behaviour 
of a person. In comparison to other diseases, Dementia is one such disease where the carers can also benefit from healthcare applications on smart devices. These applications can function as an assistive application, providing prompts to alert the user to take their medication, or provide instructions on how to perform various tasks. These applications can also take on a human computer interaction role and make use of the sensors in the device to monitor cognitive decline or behaviour. Monitoring how a person performs a task, such as taking a drink of water, can be crucial in evaluating how fast the disease progresses from person to person.

The advances in Internet of Things (IoT) related technologies over the last few years have provided new opportunities to build Quality of Life (QoL) profiles of an individual with increasing validity and reliability [7]. This has become possible by monitoring the lifelogging data captured by a variety of IoT technologies (sensors, mobile apps, web-objects, etc.) with continuous connectivity and interaction in a pervasive network. Presently, those with long-term conditions and chronic diseases require intense interactions with clinicians in a hospital environment. This can be time consuming, and the resulting assessment can be subjective. It can also be costly to the hospital and therefore not sustainable [8]. Utilizing IoT technology for home-based Dementia care will provide more accurate monitoring and deep analysis of dementia related behaviour in a home-based environment such as: gradual loss of memory, difficulty in performing familiar or complex tasks, changes in mood and disorientation. IoT technologies also allow us to consider sensitivity, social and emotional factors such as working with persons that are at various stages of the disease.

Currently there is little evidence-based literature for guiding the implementation of strategies in order to ensure an early diagnosis or to design an optimal service provision for people that suffer with the disease. The aim of this paper is to collate various papers of research and systems in order to provide insight into what technologies are currently available in the field. We will address our survey findings and provide a discussion on the advantages and disadvantages of existing technologies. This will allow us to provide our thoughts on future directions research could take in this field.

The remainder of this paper is structured as follows: Section II is focused on the current research in the field, Section III is the discussion, Section IV is focused on the research challenges and what advantages and disadvantages are present in current technologies followed by the conclusion in Section V.

\section{CURRENT RESEARCH}

Dementia related symptoms and the behaviours associated with the disease are typical classified under 6 neuropsychiatric symptoms [9]: 1) Anomalous Motor Behaviour, 2) Depression, 3) Anxiety, 4) Weight Loss, 5) Irritability, 6) Agitation. Monitoring these symptoms is possible through wearable technology.

We will begin this survey by looking at five defined types of symptoms; Wandering, Falling, Depression, Anxiety and Agitation. While there are other symptoms such as weight loss, we will focus on these five symptoms, as they are the most common in the elderly and are more likely to have an impact on the quality of life. For this survey, papers were gathered from the following online libraries; IEEE Explore, ACM Digital Library, Science Direct and Google Scholar. The following keywords and phrases were used to perform the survey; Behaviour analysis using smart devices in the elderly, wandering detection in the elderly, agitation and anxiety detection using wearable sensors in the elderly, monitoring depression with smartphones, fall detection in the elderly using smartphones and detection of agitation using smart devices. As shown in Table I, we list existing IoT technologies for elderly person care in light of three different layers, including sensors, algorithms, and applications.

\section{A. Anomalous Motor Behaviour}

Anomalous Motor Behaviour (AMB) refers to the behaviours exhibited by physical movement. This can include locationbased behaviours such as wandering which can be monitored through GPS and verbal behaviours can be viewed as motor behaviours. In order to monitor $\mathrm{AMBs}$ a range of sensor technologies can be implemented ranging from non-medical grade sensors to blind video monitoring [9].

Lifelogging the physical activity (PA) of an elderly person is vital for monitoring the health of a person. Initially attempts to capture data were performed by an external camera; however, this was considered an invasion of privacy [10]. Over recent years, various wearable trackers have been developed to monitor physical activity. Sensors such as, FitBit, Nike+ Fuelband, are gaining more attention publicly as they can record information such as heart rate and calories burnt [10]. Due to the heterogeneous nature of data sets, lifelogging PA data is generally more challenging to handle. Traditional methods require machine learning algorithms and sensors to analyse the PA, activity patterns and level of intensity. However, these methods analyse human behaviours from raw sensor data [11], [12]. With the purpose of maintaining a high accuracy when logging PA data, sensors may have to be worn on the body. These are not often cost-effective solutions in real environments [13].

Aguiar [14] presents an accelerometer-based approach for fall detection using smart phones. The paper mentions the necessity for monitoring fall detection as $40 \%$ of all mortality in older persons are caused by falls. It has also been discovered that a previous faller has a two-thirds probability of falling again within the next year. As a result, reliable fall detection and emergency assistance notification are required in order to provide suitable care and to increase the quality life of the elderly. The application itself is designed for android smartphones and aims to distinguish falls and typical activities of daily life (ADLs). Aguiar [14] has designed the application to run as a background task on the smartphone, in order to 
TABLE I. INTERNET OF THINGS ENABLED TECHNOLOGY FOR ELDERLY PEOPLE CARE

\begin{tabular}{|c|c|c|c|c|c|}
\hline $\begin{array}{c}\text { Type of } \\
\text { Symptoms }\end{array}$ & Sensors & Algorithms & Applications & Advantages & Disadvantages \\
\hline \multirow{5}{*}{ Wandering } & $\begin{array}{l}\text { Wrist Worn } \\
\text { Activity Monitor } \\
{[11],[12],[15]}\end{array}$ & $\begin{array}{c}\text { Algase } \\
\text { Wandering Scale } \\
{[15]}\end{array}$ & $\begin{array}{c}\text { Wandering } \\
\text { Behaviour Framework } \\
{[15]}\end{array}$ & $\begin{array}{l}\text { Wrist worn devices can } \\
\text { provide constant activity } \\
\text { monitoring. }\end{array}$ & $\begin{array}{l}\text { Wrist worn sensors could be } \\
\text { considered an irritant. }\end{array}$ \\
\hline & $\begin{array}{l}\text { Step Counter } \\
{[15]}\end{array}$ & $\begin{array}{l}\text { Cycles } \\
\text { Algorithm [16] }\end{array}$ & $\begin{array}{l}\text { Endomondo } \\
{[11],[12]}\end{array}$ & $\begin{array}{c}\text { Step sensors could } \\
\text { determine wandering based } \\
\text { on a constant increase of } \\
\text { steps. }\end{array}$ & $\begin{array}{l}\text { Sensor is required to be worn } \\
\text { and could be forgotten or be } \\
\text { considered irritating. }\end{array}$ \\
\hline & $\begin{array}{l}\text { Heart Rate } \\
\text { Monitor [15] }\end{array}$ & $\begin{array}{c}\text { Activity } \\
\text { Pattern Recognition } \\
{[17]}\end{array}$ & Moves [10], [11] & $\begin{array}{l}\text { Heart monitors can } \\
\text { monitor increases in heart } \\
\text { rate to determine activity. }\end{array}$ & $\begin{array}{l}\text { Heart rate can increase and } \\
\text { decrease due to a number of } \\
\text { factors, leading to inconsistent } \\
\text { results }\end{array}$ \\
\hline & $\begin{array}{l}\text { GPS [16], } \\
{[18],[19]}\end{array}$ & $\begin{array}{l}\text { Eulerian } \\
\text { Cycles [18] }\end{array}$ & $\begin{array}{c}\text { iWander } \\
\text { Application [19] }\end{array}$ & $\begin{array}{c}\text { GPS allows the } \\
\text { movements of a person to be } \\
\text { easily monitored }\end{array}$ & $\begin{array}{l}\text { Requires the devices to be on } \\
\text { the person at all times. Could } \\
\text { provide inconsistent data if } \\
\text { forgotten. }\end{array}$ \\
\hline & \multirow{2}{*}{$\begin{array}{c}\text { Tri-Axial } \\
\text { Accelerometer [17], } \\
{[20]}\end{array}$} & & SIMPATIC [18] & \multirow{2}{*}{$\begin{array}{l}\text { Increased speed in data } \\
\text { collection. Produces results } \\
\text { along all three axis. }\end{array}$} & \multirow{2}{*}{$\begin{array}{l}\text { Device has to be varied on } \\
\text { the person's body. Can be } \\
\text { forgotten or could lose connection } \\
\text { if device is wired. }\end{array}$} \\
\hline \multirow{4}{*}{ Falling } & & $\begin{array}{r}\text { Tri-Axial } \\
\text { Accelerometer } \\
\text { Algorithm [20] }\end{array}$ & & & \\
\hline & $\begin{array}{l}\text { Floor Sensor } \\
{[21]}\end{array}$ & $\begin{array}{c}\text { Event } \\
\text { Detection and } \\
\text { Segmentation [21] }\end{array}$ & $\begin{array}{l}\text { Fall Detection } \\
\text { Application [22] }\end{array}$ & $\begin{array}{l}\text { Can accurately detect a } \\
\text { person falling on the floor. }\end{array}$ & $\begin{array}{l}\text { Could detect other objects } \\
\text { falling onto the floor, providing } \\
\text { inaccurate results. }\end{array}$ \\
\hline & $\begin{array}{l}\text { Accelerometer } \\
{[14],[22]-[24]}\end{array}$ & $\begin{array}{c}\text { Discrete } \\
\text { Wavelet Transform } \\
{[22]}\end{array}$ & $\begin{array}{c}\text { Android } \\
\text { Smartphone } \\
\text { Application [14] }\end{array}$ & $\begin{array}{c}\text { Can detect sudden } \\
\text { movements involved in a fall. }\end{array}$ & $\begin{array}{l}\text { Device could be dropped, } \\
\text { producing a fall result. }\end{array}$ \\
\hline & $\begin{array}{l}\text { Pulse Sensors } \\
{[23],[25]}\end{array}$ & $\begin{array}{c}\text { State Machine } \\
\text { Based Algorithm } \\
{[16]}\end{array}$ & $\begin{array}{l}\text { Pulse Wave } \\
\text { Smartphone } \\
\text { Application [25] }\end{array}$ & $\begin{array}{c}\text { Pulse sensors can } \\
\text { notice changes in heart rate, } \\
\text { which could signal a fall. }\end{array}$ & $\begin{array}{l}\text { Device can be forgotten by } \\
\text { person, leading to a gap in data } \\
\text { collection. Other factors can also } \\
\text { cause changes in heart rate. }\end{array}$ \\
\hline \multirow{4}{*}{ Depression } & $\begin{array}{c}\text { Sleep } \\
\text { Monitoring [26] }\end{array}$ & $\begin{array}{c}\text { Formant } \\
\text { Tracking Algorithm } \\
{[27]}\end{array}$ & $\begin{array}{l}\text { Touchscreen } \\
\text { driven UI [26] }\end{array}$ & $\begin{array}{l}\text { Amount of sleep can } \\
\text { signal whether someone is } \\
\text { depressed }\end{array}$ & $\begin{array}{l}\text { Wearing the sensor of a night } \\
\text { could be irritating for the person. }\end{array}$ \\
\hline & $\begin{array}{c}\text { Video } \\
\text { Monitoring [27] }\end{array}$ & $\begin{array}{c}\text { Dictionary } \\
\text { Learning Algorithm } \\
{[27]}\end{array}$ & Daybuilder [28] & $\begin{array}{l}\text { Video monitoring is } \\
\text { accurate in detecting signs of } \\
\text { depression. }\end{array}$ & $\begin{array}{l}\text { Privacy concerns can } \\
\text { outweigh the benefits from using } \\
\text { video monitoring. }\end{array}$ \\
\hline & $\begin{array}{c}\text { Audio } \\
\text { Monitoring [27], } \\
{[29]}\end{array}$ & $\begin{array}{c}\text { Minimal- } \\
\text { redundancy- } \\
\text { maximal-relevance } \\
{[29]}\end{array}$ & $\begin{array}{l}\text { BBD Android } \\
\text { Application [30] }\end{array}$ & $\begin{array}{c}\text { Voices of depressed } \\
\text { persons have specific } \\
\text { characteristics that allow for } \\
\text { detection of symptoms. Also } \\
\text { non-invasive and portable. }\end{array}$ & $\begin{array}{l}\text { If sensor is forgotten then } \\
\text { data collection cannot be } \\
\text { performed. }\end{array}$ \\
\hline & $\begin{array}{l}\text { Body Sensors } \\
\text { [31] }\end{array}$ & $\begin{array}{c}\text { Machine } \\
\text { Learning } \\
\text { Algorithms [31] }\end{array}$ & Mobilyze [31] & $\begin{array}{l}\text { A sensor network can } \\
\text { perform constant monitoring } \\
\text { of activities. }\end{array}$ & $\begin{array}{l}\text { Relies on the person to } \\
\text { remember to wear the sensors. } \\
\text { Persons could be irritated by } \\
\text { wearing devices constantly. }\end{array}$ \\
\hline \multirow{3}{*}{$\begin{array}{l}\text { Anxiety \& } \\
\text { Agitation }\end{array}$} & $\begin{array}{l}\text { Heart Monitor } \\
\text { [32] }\end{array}$ & $\begin{array}{l}\text { Blink Event } \\
\text { Algorithm [32] }\end{array}$ & $\begin{array}{l}\text { Google Glass } \\
\text { Application [32] }\end{array}$ & $\begin{array}{l}\text { Heart monitors can } \\
\text { monitor increases in heart } \\
\text { rate to determine activity. }\end{array}$ & $\begin{array}{c}\text { Heart monitors can monitor } \\
\text { increases in heart rate to determine } \\
\text { activity. }\end{array}$ \\
\hline & $\begin{array}{l}\text { Body Sensor } \\
\text { Network [33] }\end{array}$ & $\begin{array}{l}\text { Peak Detection } \\
\text { [34] }\end{array}$ & StressSense [35] & $\begin{array}{c}\text { A sensor network can } \\
\text { perform constant monitoring } \\
\text { of activities. }\end{array}$ & $\begin{array}{l}\text { Relies on the person to } \\
\text { remember to wear the sensors. } \\
\text { Persons could be irritated by } \\
\text { wearing devices constantly. }\end{array}$ \\
\hline & $\begin{array}{c}\text { Video } \\
\text { Monitoring [9] }\end{array}$ & $\begin{array}{l}\text { Joint Time- } \\
\text { Frequency } \\
\text { Algorithms [33] }\end{array}$ & TEMPO3 [33] & $\begin{array}{l}\text { Video monitoring is } \\
\text { accurate in detecting signs of } \\
\text { agitation. }\end{array}$ & $\begin{array}{l}\text { Privacy concerns can } \\
\text { outweigh the benefits from using } \\
\text { video monitoring. }\end{array}$ \\
\hline
\end{tabular}


monitor all of the users movements to detect a fall. The system will sound an alarm if a fall is detected as well as providing an SMS message to a set list of contacts. The proposed solution for the application considers an algorithm based on a state machine. The algorithm recognizes the stages of a fall and will trigger an alarm if the stages are recognized in the correct order. Transitioning between stages is performed by monitoring changes in the computing signals, using offline classification algorithms to obtain thresholds.

The method proposed by Kim [17] uses tri-axis acceleration sensors to digitalize the behaviour of the elder by monitoring daily activities. Activities are categorised as Low and High level. Low level refers to physical movements such as walking, running and lying. This data can be detected with sensors as they can recognize when the subject moves and how long the subject has moved. High-level activities are predicted by time and place, for example sleeping. This information is unreliable, as it requires some guesswork on the part of the researcher as it is difficult to recognise the activity through the raw sensor data.

Yavuz [22] proposes a fall detection system for android smart phones that incorporates different algorithms and accelerometers on the phone in order to create a robust fall detection system. Yavuz suggests that using a 1-D Fourier frequency is not sufficient for detecting falls using accelerometer signals. The alternative proposed is the wavelet transformation method as this allows for temporal localization of frequency components.

Discrete wavelet transform (DWT) is able to yield a multiscale representation of discrete signals, which are formed by applying analysis filters to the original signal. For their application, Yavuz [22] uses DWT as a feature extraction method. The DWT method is applied to a discrete acceleration signal provided by the accelerometer integrated into the phone. If the values of the coefficients that are extracted from the accelerometer are above the threshold, then a fall is detected. The application is designed for users who may be susceptible to sudden falls like the elderly, those with epilepsy or mild cognitive impairment such as dementia sufferers. It allows alerts to be sent to carers as well as to contacts over social media should a sudden fall occur.

Fall detection solutions can have their disadvantages. One example being the "Social Alarm" [21] as this requires the user to press a button. After a fall, a person could be unconscious or panicked and as a result unable to press the button to alert a carer. The most popular solution, the wearable fall detector that are based on accelerometers and tilt sensors, require the person to wear the device constantly, such as in the shower where the risk of a fall is greatest [21].

Video based analysis techniques rely on image processing of a person's movements in real time. The video system must be able to detect objects, extract features such as speed and be able to determine if a human fall has occurred. However, this presents challenges, as it can be difficult to monitor an entire house and this technique has a number of privacy concerns [21]. However, in situations where it can be deemed appropriate, video can provide more information than simple motion related data. The example given in [9] is the problem of ensuring elderly people have sufficient nutrition as they can sometimes forget to eat. In this situation, video capture could be used to monitor body mass changes.

\section{B. Anxiety}

Miranda et al. [32] proposes an application that detects anxiety through wearable sensors. Three devices are employed to monitor heart rate and spontaneous blink rate. The custom application was developed to transfer data produced by Google Glass and a Bluetooth zephyr HxM band to a server. The setup involved a dedicated router to reduce transfer delays and other common issues found in scholar networks in order to prevent data loss during data transfer between application and server. Miranda et al. coded their algorithm in Java based on the approach by Ishimaru [36] with some minor modifications. Sensor readings were tracked to detect when data hits a peak value to identify the blink event. When a peak was detected, it would be recognised as a blink.

The Google Glass application proposed by [32] allowed data to be gathered by the IR sensor in order to detect agitation through blink rate. The IR sensor measures the distance between the device and the user's eye, and can determine a blink event as a result. However, the disadvantage of this could be due to the requirement to wear the Google Glass device constantly in order to establish when the person is agitated and could agitate the user because of this requirement. This method could also be seen as unreliable as the user could experience sudden relaxation which could affect results, as pointed out in [32].

Bankole et al.[33] uses body sensor networks for continuous longitudinal agitation assessment. A multitrait-multimethod approach is used to test the validity of the body sensor network. Three clinical instruments (Aggressive behaviour scale, CohenMansfield Agitation Inventory, Mini Mental State Examination) with strong validity and reliability were used as benchmarks to test convergent and discriminant validity of the BSN.

The TEMPO3 network proposed by Bankole [33] consists of up to eight wireless inertial body sensors that gather data from persons while they perform normal daily activities. The motion capture capabilities provided by TEMPO allow for six degrees of freedom, sensing at arbitrary frequencies with 12-bit resolution. This enables higher resolution analyses of persons' movements and potentially higher precision assessments of agitation, as it is essential to differentiate normal movement from agitated movement. Battery life on the devices is limited 
to $\sim 5$ hours when all six sensors are streaming the raw data via a Bluetooth transceiver. When the gyroscopes are turned off, the battery life increases to $\sim 9$ hours. This is done as only the accelerometers are used in the study by Bankole [33]. Local storage of the data instead of transmitting it wirelessly increases the battery life further, which would be permitted in a clinical deployment of the system.

Lu et al. [35] studied stress associated with the cognitive load experienced by a participant during a job interview as an interviewee and conducting a marketing task as an employee. Neutral tasks were also considered, where participants are not under stress. These three tasks are designed with the help of behavioural psychologists. As with SUSAS (Speech under Simulated and Actual Stress) and other previous studies [37][39], it is assumed that the subject's voice are stressed once the stressor is present and reading without stressor is neutral. Audio was continuously collected using a Google Nexus One Android smartphone and a microcone 1 microphone array. In addition to audio data, video cameras record the interviewer and interviewee. In addition to capturing stressed audio, we also collect audio data from neutral scenarios where participants are not stressed. In neutral scenarios, participants had to read both indoor and outdoor. The reading materials are simple stories that often used to study different accents in languages.

\section{Depression}

Gruenerbl et al. [40] gave each participant an Android smart phone that ran a logging application developed by their group. The application contained two major components; a data logger (using the standard Android API) with the person having the option of turning off the logging at any time and a selfassessment questionnaire (set to pop-up at the end of the day). After finishing the questionnaire, the person would be asked whether they were comfortable with logging the day's data. The data would be stored on an SD card and was copied during the periodic examination and stored in a form that would not reveal the person's identity to the researchers working on the data later on. Clearly, in a "productive" system the data would need to be transmitted wirelessly at the end of each day. However, for the purpose for the research by Gruenerbl et al. [40] the SD card option was more reliable and allowed us to simplify data security issues.

Canzian [41] uses the Android application MoodTraces that automatically samples phone sensors to retrieve the current location, which is represented by a time reference, a longitude value, and a latitude value. Additional information about the phone usages and user activities extracted using the Android API are also collected, but they are not analysed directly in this work, given its specific focus on mobility pattern analysis. Activity information is also used to optimize the sampling process. In addition to sensor-based data, MoodTraces collects the answers that the users provide to daily questionnaires.
Burns [31] used a single-arm field trial of Mobilyze, an 8 week multimodal intervention for depression that included 1) mobile phone sensing and ecological momentary intervention 2) an interactive website for behavioural skills training and 3) email and telephone support from a coach assigned to each participant. The context aware system used an architecture consisting of 3 phases. Phase 1 uses sensors that are housed on the mobile phone to perform observations of the participants and their environment. Phase 2 used an algorithm to inductively learn the relationship between the sensor data and the participants recorded social context, activity, location and internal states. Phase 3 consisted of action components that provided mechanisms for relaying predictions to other external outreach applications.

There are several sleep monitoring systems on the market to date that can aid in the detection of depression [26]. Polysomnography devices are the most accurate however, the drawbacks to these devices include the expensive price tag as they require monitoring from professionals and they must be worn. A solution to this is to use three independent tri-axial accelerometers to send data wirelessly to be processed by a laptop. This allows for the amount of deflection to be determined when a person's weight is applied to the mattress. If deflection exceeds a predetermined threshold then movement has occurred. An advantage of this approach is that the true orientation of the accelerometer does not have to be determined in order to measure movement. Monitoring can also continue even if the sensors have been knocked out of place. Another advantage to this method is that noise is eliminated, increased scalability and lower storage requirements due to the fact only discrete events are stored [26].

\section{DISCUSSION}

The advancement in sensor technologies over recent years has allowed researchers to provide innovative ways to monitor behaviour in uncontrolled environments. Monitoring the elderly this way provides significant advantages over doing so in a controlled environment as privacy concerns can be alleviated as well as providing constant monitoring in order to produce accurate data. This method also allows costs to be reduced as these sensors are cheaper and are typically found within mobile phones.

For an elderly person that suffers with irritability, being forced to wear sensors constantly could provide some discomfort. Instead, using a smart phone could help alleviate some of this discomfort while still maintaining frequent, noninvasive monitoring of their behaviour. However, the issue with doing this means that data collection could be stopped should the elderly person forget to pick up the device or turn off the sensing application. This means that data collection is not as efficient as sensors that are required to be worn; however, this 
may be a sacrifice necessary to ensure that the person remains at ease.

Monitoring behaviour in uncontrolled environments allows researchers to capture the natural behaviour of the person. This allows researchers to have new possibilities for monitoring events such as lifestyle, fitness and detecting stress. There are advantages to doing this, as it becomes possible to detect changes in behaviour in a person, which can signal symptoms of depression in some circumstances. Employing smartphones and sensors to monitor lifestyle and fitness behaviour allows data collection to become more efficient.

Smart phone devices and wearable sensors can also be cost effective. A typical household will have a smart phone and does not require monitoring by a professional. Additional wearable sensors will require some additional cost; however, these sensors are not too expensive and only require a device such as a smartphone or a laptop to pair with in order to share data. This allows for monitoring behaviour in uncontrolled environments to be conducted more frequently and efficiently.

More accurate forms of data collection, such as video capture, create privacy concerns. The majority of people do not want to be monitored in this way on a frequent basis. Instead performing analysis on voice patterns, weight gain or loss, and general activity through wearable sensors and smart phones can provide sufficient data to a researcher. However, this is done at the cost of accuracy. Using sensors that provide basic data on voice patterns, movement, location and activity are necessary to provide constant monitoring to a person in order to maintain monitoring of their behaviour and to maintain their privacy as much as possible.

\section{RESEARCH CHALLENGES}

\section{A. Involvement of Human Factors}

Sensor networks have been used frequently and comprehensively in smart home environments as well as hospitals for health monitoring. Environment data is captured by the sensors and sent to a processing unit for analysis using various methods to produce a meaningful output to clinicians and healthcare professionals. The disadvantage of using sensor networks like this to continuously monitor a person are the privacy concerns involved. The implementation of technologies in a health care environment are generally impeded by these concerns as the continuous monitoring may intrude on the decision making of a person and privacy. One solution could be to use a Body Sensor Network, as these cannot intrude on a person's privacy to severely. However as these sensors are required to be worn, they could cause irritability for an elderly person and they may choose to take it off. This would lead to a gap in data collection.

The use of sensors that can be placed on the body of the person, such as on the wrist, can provide efficient data on the person's action in order to detect wandering and falls. Smart phones can also be used for fall and wandering detection, however an elderly person could possibly forget to pick up the device and keep it on them meaning no data would be produced. The disadvantage to using ambient sensors and wearable sensors as opposed to video capture is that the methods used are generally less accurate. However due to the privacy concerns of the video, these sensors are typically preferred in research.

\section{B. Mobility}

The advancements in sensor technology over recent years has allowed the technology to move into mobile devices. The use of smart phones for sensing various behaviours in a person comes with its benefits as phones come with sensors such as gyroscopes and accelerometers already built in. They are also cheaper than some wearable sensors and typically, a person would have one in their household. However, someone with dementia could easily forget a smart phone. For fall and wandering detection, this could prove problematic, as there could potentially be periods were no data collection is occurring. The ability to consistently monitor a person's physical activity through the built in accelerometer and obtain a clearer idea of a person's physical events can be concluded. The advantage to using a mobile device for research is the popularity of the devices, which allows for monitoring in an uncontrolled environment outside of a laboratory. This means that the natural behaviour of a person can be captured.

TABLE II. LIST OF RESEARCH CHALLENGES AND CAUSES

\begin{tabular}{|c|c|}
\hline Research Challenge & Cause \\
\hline \multirow{5}{*}{$\begin{array}{c}\text { Involvement of Human } \\
\text { Factors }\end{array}$} & Potentially invasive to person \\
\hline & Privacy concerns \\
\hline & Forgetfulness of the person \\
\hline & Potentially less accurate \\
\hline & Sensor could be an irritant \\
\hline \multirow[t]{2}{*}{ Mobile } & Gaps in data collection \\
\hline & Potentially forgotten by person \\
\hline \multirow[t]{2}{*}{$\begin{array}{l}\text { Uncontrolled } \\
\text { Environments }\end{array}$} & $\begin{array}{c}\text { Sensors could be required to be } \\
\text { worn }\end{array}$ \\
\hline & $\begin{array}{l}\text { Sensor must be able to adapt to } \\
\text { different environments }\end{array}$ \\
\hline \multirow[t]{3}{*}{ Issues with Sensors } & $\begin{array}{l}\text { May require professional } \\
\text { monitoring }\end{array}$ \\
\hline & Cost of sensor \\
\hline & Requires a paired device \\
\hline
\end{tabular}




\section{Uncontrolled Environments}

Using voice recording to detect behavioural patterns in speech is a way to monitor a person for signs on depression. The advantages to this method are the unique characteristics that are produced in the voice of a depressed person such as stuttering and whispering, as noted in previous studies. In order to operate effectively a voice based sensor needs to cope with both the diverse acoustic environments as well as individual variabilities portraying stress in order to diagnose depression. Typically high quality microphones were needed in monitoring voice signals, however smart phones have become used in research as it allows for adaptation to individual environments. Using voice signals to detect behavioural patterns in speech can also be seen as non-invasive as no personal data on the person is stored. The sensor required can also be portable, allowing for an effective method of detecting depression.

Sleep monitoring is also an effective method for monitoring behaviour. Depression can be associated with a lack of sleep and disturbed sleep however, typical sensors, while accurate, are required to be worn in order for monitoring to take place. They also require professional monitoring and are therefore expensive to use. The assessment and treatment of a person can also be affected by the lack of objective data to match selfreports by the monitored person. An objective tool for monitoring symptoms could help improve the accuracy of the self-reports by the person allowing for effective treatment to take place.

\section{Issues with Sensors}

Using wearable devices as an alternative to this does provide more consistent data collection as the device will be worn frequently. However, the requirement to wear the device consistently could irritate a person suffering from cognitive decline, as they may not wish to wear a device constantly and therefore may not be practical. Wearable devices also require a paired device that the data will be sent to such as a laptop. This means it may have to stay in the vicinity of the paired device in order to function as intended.

\section{CONCLUSION}

This paper has presented various methods of behaviour analysis techniques from an IoT perspective. Various aspects required for behavioural analysis have been included such as; sensors, algorithms and applications. This survey examined the five major behaviours in the elderly, which can be linked to dementia and the sensing technologies and algorithms that are used to monitor these behaviour patterns. This paper discussed and extracted possible research topics for further investigation in real life, uncontrolled environments. Finally, this paper also looked at the advantages and disadvantages of existing technologies for monitoring behaviour in uncontrolled environments. This survey aimed to provide an insight into the latest IoT enabled technologies and provide advantages and disadvantages for potential future research opportunities. As a result we believe that the issues of privacy and maintaining a cost effective method to effectively gather data in an uncontrolled environment would be the primary focus for future IoT enabled technologies in future implementations of technology.

\section{REFERENCES}

[1] Alzheimer's Society, “About dementia," 2014. [Online]. Available: https://www.alzheimers.org.uk. [Accessed: 10-Aug-2016].

[2] S. Finkel and J. C. e Silva, "Behavioral and psychological signs and symptoms of dementia: a consensus statement on current knowledge and implications for research and treatment," Int. ..., vol. 12, no. February, pp. 1060-1061, 1997.

[3] M. Yefimova and D. L. Woods, "Using Sensor Technology to Monitor Disruptive Behavior of Persons With Dementia," AAAI Fall Symp. Ser. 2012 AAAI Fall Symp. Ser., pp. 51-54, 2012.

[4] J. Coppola, M. Kowtko, C. Yamagata, and S. Joyce, "Applying Mobile Application Development to Help Dementia and Alzheimer Patients," Csis.Pace.Edu, pp. 1-7, 2013.

[5] S. Michie, "The Behaviour Change Wheel: a new method for characterising and designing behaviour change interventions Why focus on behaviour?," vol. 42, no. April, 2015.

[6] M. Ziefle and R. Carsten, "Acceptance of Pervasive Healthcare Systems: A comparison of different implementation concepts," Comput. Technol. Healthc. (, pp. 1-6, 2010.

[7] J. Healey, "Future possibilities in electronic monitoring of physical activity.," Res. Q. Exerc. Sport, vol. 71, no. September, pp. S137S145, 2000.

[8] J. Qi, L. Chen, W. Leister, and S. Yang, "Towards knowledge driven decision support for personalized home-based self-management of chronic diseases," Proc. - 2015 IEEE 12th Int. Conf. Ubiquitous Intell. Comput. 2015 IEEE 12th Int. Conf. Adv. Trust. Comput. 2015 IEEE 15th Int. Conf. Scalable Comput. Commun. 20, pp. 1724-1729, 2016.

[9] P. Moore, F. Xhafa, L. Barolli, and A. Thomas, "Monitoring and detection of agitation in dementia: Towards real-time and big-data solutions," Proc. - 2013 8th Int. Conf. P2P, Parallel, Grid, Cloud Internet Comput. 3PGCIC 2013, pp. 128-135, 2013.

[10] J. Qi, P. Yang, M. B. Hanneghan, and S. Tang, "Multiple Density Maps Information Fusion for Effectively Assessing Intensity Pattern of Lifelogging Physical Activity," Neurocomputing, no. 286545, 2016.

[11] J. Qi, P. Yang, M. Hanneghan, D. Fan, Z. Deng, and F. Dong, "Ellipse fitting model for improving the effectiveness of life-logging physical activity measures in an Internet of Things environment," pp. 107113, 2016.

[12] P. Yang, M. Hanneghan, J. Qi, D. Fan, Z. Deng, and F. Dong, "Improving the Validity of Lifelogging Physical Activity Measures in an Internet of Things Environment," IET Networks, vol. 5, no. 5, pp. 107-113, 2016.

[13] J. Qi, P. Yang, D. Fan, and Z. Deng, "A Survey of Physical Activity Monitoring and Assessment Using Internet of Things Technology," Comput. Inf. Technol. Ubiquitous Comput. Commun. Dependable, Auton. Secur. Comput. Pervasive Intell. Comput. (CIT/IUCC/DASC/PICOM), 2015 IEEE Int. Conf., pp. 2353-2358, 2015.

[14] B. Aguiar, T. Rocha, and J. Silva, "Accelerometer-Based Fall Detection for Smartphones," 2014

[15] T. Toutountzi and S. Phan, "A Framework for the Assessment of Wandering Behavior."

[16] E. Batista, F. Borras, F. Casino, and A. Solanas, "A Study on the Detection of Wandering Patterns in Human Trajectories," pp. 1-6.

[17] K. Kim, M. M. Hassan, S. Na, and E. Huh, "Dementia Wandering Detection and Activity Recognition Algorithm Using Tri-axial Accelerometer Sensors," 2009.

[18] A. Solanas, E. Batista, F. Borras, and C. Patsakis, "Wandering Analysis with Mobile Phones On the Relation Between Randomness 
and Wandering."

[19] F. Sposaro, J. Danielson, and G. Tyson, "iWander: An Android Application for Dementia Patients," pp. 3875-3878, 2010.

[20] A. K. Bourke, J. V. O. Brien, and G. M. Lyons, "Evaluation of a threshold-based tri-axial accelerometer fall detection algorithm," vol. 26, pp. 194-199, 2007.

[21] Y. Zigel, D. Litvak, and I. Gannot, "A Method for Automatic Fall Detection of Elderly People Using Floor Vibrations and Sound Proof of Concept on Human Mimicking Doll Falls," vol. 56, no. 12, pp. 2858-2867, 2009

[22] G. R. Yavuz, M. E. Kocak, G. Ergun, H. Alemdar, H. Yalcin, O. D. Incel, L. Akarun, and C. Ersoy, "A Smartphone Based Fall Detector with Online Location Support."

[23] J. Wang, Z. Zhang, B. Li, S. Lee, and R. S. Sherratt, “An Enhanced Fall Detection System for Elderly Person Monitoring using Consumer Home Networks," pp. 23-29, 2014.

[24] F. G. Miskelly, "Assistive technology in elderly care.," Age Ageing, vol. 30, no. 6, pp. 455-458, 2001.

[25] W. Azizul, S. Imai, and T. Hasegawa, "Fall detection using smart phone and ubiquitous pulse wave sensor," no. microS D, pp. 3-6.

[26] R. F. Dickerson, T. Hnat, E. Hoque, and J. a Stankovic, "Demonstration of sleep monitoring and caregiver displays for depression monitoring," Proc. 2nd Conf. Wirel. Heal. - WH'11, p. 1, 2011.

[27] J. R. Williamson, E. Godoy, M. Cha, A. Schwarzentruber, P. Khorrami, Y. Gwon, H.-T. Kung, C. Dagli, and T. F. Quatieri, "Detecting Depression using Vocal, Facial and Semantic Communication Cues," Proc. 6th Int. Work. Audio/Visual Emot. Chall. - AVEC '16, pp. 11-18, 2016.

[28] P. Loventoft, L. Norregaard, and E. Frokjær, "Designing daybuilder: an experimental app to support people with depression," Proc. the $12^{\text {th }}$ Participatory Design Conference: Exploratory papers, Workshop description, Industry Cases, Vol.2, pp. 1-4, 2012.

[29] Z. Liu, B. Hu, L. Yan, T. Wang, F. Liu, X. Li, and H. Kang, "Detection of depression in speech," 2015 Int. Conf. Affect. Comput. Intell. Interact. ACII 2015, pp. 743-747, 2015.

[30] A. Doryab, J. K. Min, J. Wiese, J. Zimmerman, and J. I. Hong, "Detection of behavior change in people with depression," $A A A I$ Work. Work. Twenty-Eighth AAAI Conf. Artif. Intell., pp. 12-16, 2014.
[31] M. N. Burns, M. Begale, J. Duffecy, D. Gergle, C. J. Karr, E. Giangrande, and D. C. Mohr, "Harnessing context sensing to develop a mobile intervention for depression," J. Med. Internet Res., vol. 13, no. 3, pp. 1-17, 2011

[32] D. Miranda, M. Calderón, and J. Favela, "Anxiety detection using wearable monitoring," pp. 34-41, 2014.

[33] A. Bankole, M. Anderson, A. Knight, K. Oh, T. Smith-Jackson, M. a. Hanson, A. T. Barth, and J. Lach, "Continuous, non-invasive assessment of agitation in dementia using inertial body sensors," Proc. 2nd Conf. Wirel. Heal. - WH'11, p. 1, 2011.

[34] V. Foo, S. Fookt, P. V. Thangt, T. M. Htwet, Q. Qiangt, A. Aung, P. Wait, M. Jayachandrant, J. Biswas, P. Yapt, A. Hospital, and A. Road, "Automated Recognition of Complex Agitation Behavior of Dementia Patients Using Video Camera," pp. 68-73, 2007.

[35] H. Lu, D. Frauendorfer, M. Rabbi, M. S. Mast, G. T. Chittaranjan, A. T. Campbell, D. Gatica-Perez, and T. Choudhury, "StressSense: Detecting Stress in Unconstrained Acoustic Environments using Smartphones," Proc. 2012 ACM Conf. Ubiquitous Comput. UbiComp '12, p. 351, 2012.

[36] S. Ishimaru, K. Kunze, and K. Kise, "In the Blink of an Eye Combining Head Motion and Eye Blink Frequency for Activity Recognition with Google Glass," Ah, p. 15:1-15:4, 2014.

[37] J. H. L. Hansen and S. Bou-Ghazale, "Getting started with SUSAS: A speech under simulated and actual stress database," Proc EuroSpeech, 1997.

[38] R. Fernandez and R. W. Picard, "Modeling drivers' speech under stress," Speech Commun., vol. 40, no. 1-2, pp. 145-159, 2003.

[39] S. A. Patil and J. H. Hansen, "Detection of speech under physical stress: model development, sensor selection, and feature fusion," Interspeech. 2008.

[40] A. Gruenerbl, V. Osmani, G. Bahle, J. C. Carrasco, S. Oehler, O. Mayora, C. Haring, and P. Lukowicz, "Using smart phone mobility traces for the diagnosis of depressive and manic episodes in bipolar patients," Proc. 5th Augment. Hum. Int. Conf., p. 38, 2014.

[41] L. Canzian and M. Musolesi, "Trajectories of depression," Proc. 2015 ACM Int. Jt. Conf. Pervasive Ubiquitous Comput. - UbiComp '15, pp. 1293-1304, 2015. 